\title{
Atividade inseticida do óleo essencial de Hyptis marrubioides no controle de Zabrotes subfasciatus (Coleoptera, Chrysomelidae, Bruchinae)
}

Marcelo Barboza de Mello1 ${ }^{1}$.

Priscila Pereira Botrel².

Isabel Ribeiro do Valle Teixeira ${ }^{3}$.

Felipe Campos Figueiredo ${ }^{4}$.

José Eduardo Brasil P. Pinto 5 .

Suzan Kelly Vilela Bertoluccí.

\section{Resumo}

Sabe-se que uma grande porcentagem da produção e do armazenamento dos grãos de feijão é perdida pelo consumo de insetos. Este trabalho teve como objetivo avaliar a atividade inseticida do óleo essencial de Hyptis marrubioides no controle de Zabrotes subfasciatus. A extração do óleo essencial foi realizada pelo método de hidrodestilação em aparelho de Clevenger, por uma hora e meia e o ensaio biológico foi conduzido no Laboratório de Microscopia/IFSULDEMINAS, Campus Muzambinho. O delineamento experimental utilizado foi inteiramente casualizado, constituído de cinco concentrações de óleo essencial (0,0; 6,25\%; 12,5\%; 25\% e 50\%), com quatro repetições contendo um casal de Z. subfasciatus por repetição. Realizou-se o teste de mortalidade e inibição de oviposição. Utilizou-se três grãos de feijão tratados com 5 microlitros $(\mu \mathrm{L})$ de solução e três não tratados, caracterizando assim um teste com chance de escolha. Como controle, utilizou-se $100 \mu \mathrm{L}$ de álcool $70 \%$. Após a aplicação dos tratamentos, observou-se a reação dos indivíduos de Z. subfasciatus, evidenciando que os Tempos Letais (TL) diminuem conforme há um aumento e contato direto dos insetos com as concentrações do óleo essencial de $H$. marrubioides. A aplicação do óleo essencial foi bastante efetiva, pois ocorreu mortalidade total dos insetos adultos e nenhuma oviposição. $O$ intervalo de tempo de 28 minutos foi suficiente para provocar mortalidade de todos os indivíduos. Foi possível observar que o óleo essencial de H. marrubioides possui efeito inseticida sobre Z. subfasciatus, podendo auxiliar no manejo integrado de Z. subfasciatus em feijão armazenado.

Palavras-chave: Hortelã-do-campo. Planta medicinal. Inseticida natural. Caruncho-do-feijão.

\footnotetext{
${ }^{1}$ Instituto Federal do Sul de Minas Gerais, Campus Muzambinho, IFSULDEMINAS, graduado em Ciências Biológicas. Muzambinho, Minas Gerais, Brasil.ndbbravo@gmail.com. Estrada de Muzambinho, Km 35, Bairro Morro Preto, Cx. Postal 02, Muzambinho, Minas Gerais, Brasil. CEP 37890-000.

2 Instituto Federal do Sul de Minas Gerais, Campus Muzambinho, IFSULDEMINAS, professora pesquisadora. Muzambinho, Minas Gerais, Brasil.priscila.botrel@muz.ifsuldeminas.edu.br. (35) 3571-5051. Estrada de Muzambinho, Km 35, Bairro Morro Preto, Cx. Postal 02, Muzambinho, Minas Gerais, Brasil. CEP 37890-000.

${ }^{3}$ Instituto Federal do Sul de Minas Gerais, Campus Muzambinho, IFSULDEMINAS, professora pesquisadora. Muzambinho, Minas Gerais, Brasil.ribeirodovalleteixeira@hotmail.com.. (35) 3571-5051. Estrada de Muzambinho, Km 35, Bairro Morro Preto, Cx. Postal 02, Muzambinho, Minas Gerais, Brasil. CEP 37890-000.

${ }^{4}$ Instituto Federal do Sul de Minas Gerais, Campus Muzambinho, IFSULDEMINAS, professor pesquisador. Muzambinho, Minas Gerais, Brasil. felipe.figueiredo@muz.ifsuldeminas.edu.br.(35) 3571-5051. Estrada de Muzambinho, Km 35, Bairro Morro Preto, Cx. Postal 02, Muzambinho, Minas Gerais, Brasil. CEP 37890-000.

${ }^{5}$ Universidade Federal de Lavras, UFLA, professor pesquisador. Lavras, Minas Gerais, Brasil. jeduardo@dag.ufla.br. Departamento de Agricultura, Cx Postal 3037, Lavras, Minas Gerais, Brasil. CEP 37.200-000.

${ }_{6}^{6}$ Universidade Federal de Lavras, UFLA, professora pesquisadora. Lavras, Minas Gerais, Brasil. suzan@dag.ufla.br. Departamento de Agricultura, Cx Postal 3037, Lavras, Minas Gerais, Brasil. CEP 37.200-000.
} 


\section{Introdução}

Dentre as famílias vegetais conhecidas e utilizadas popularmente e, portanto, com elevado potencial químico, ricas em espécies aromáticas de grande importância econômica (SIMÕES; SPITZER, 2000), encontra-se a Lamiaceae com aproximadamente duzentos e sessenta e quatro gêneros descritos (USDA, 2007). Hyptis marrubioides Epl. é uma espécie pertencente a esta família, endêmica da região do cerrado brasileiro e conhecida popularmente como hortelã do campo.

O gênero Hyptis Jacq (Lamiaceae) inclui cerca de trezentas espécies de ampla ocorrência na América Tropical (WILLIS, 1973; HARLEY, 1988). Plantas desse gênero apresentam grande importância como fonte de constituintes bioativos, possuindo vários efeitos biológicos, como atividades antimicrobianas, citotóxicas e inseticidas (KUHNT et al., 1995).

Zabrotes subfasciatus é classificado como uma praga secundária de grãos, pois se utiliza principalmente de sementes já processadas, em armazenamento. As fêmeas, após selecionar o sítio de oviposição, colocam os ovos na superfície externa do grão e a larva, quando eclode, penetra diretamente para o interior deste grão, consumindo seus tecidos internos. Todos os estágios imaturos (larval e pupa) são desenvolvidos dentro do grão, de onde o inseto sai apenas quando se torna adulto (TEIXEIRA; ZUCOLOTO, 2003). No caso do feijão, leguminosa de maior importância como fonte de proteína vegetal no Brasil, o desenvolvimento deste inseto, afeta negativamente a aparência, palatabilidade e aceitabilidade do grão pelo consumidor. Nesses grãos ocorre significante redução da qualidade nutricional, perda de peso e depreciação comercial devido, não apenas à presença de insetos, como também de seus fragmentos (HOHMANN; CARVALHO, 1989). Em sementes, a germinação e o vigor podem ser reduzidos, significantemente, devido ao ataque de insetos (OLIVEIRA et al., 1979).

Atualmente, os inseticidas naturais têm sido cada vez mais requisitados pelo mercado, principalmente pelo aumento da pressão do consumo cada vez mais consciente, pois estes inseticidas apresentam inúmeras vantagens quando comparados ao emprego de seus pares sintéticos, como a de serem obtidos de recursos renováveis e por serem rapidamente degradados, não deixando resíduos nem nos alimentos nem no meio ambiente.

O desenvolvimento destes compostos requer tempo e também um estudo sistematizado que preencha requisitos, tais como seletividade contra inimigos naturais, baixa toxicidade para mamíferos, biodegradabilidade e ausência de fitotoxicidade, além dos requisitos econômicos para que sua produção em alta escala seja viável (VIEIRA et al., 2001).

Os efeitos dos inseticidas botânicos sobre os insetos são variados, podendo ser tóxico, repelente, causar esterilidade, modificar o comportamento, o desenvolvimento ou reduzir a alimentação (ARNASON et al., 1990; BELL et al., 1990). A ação tóxica de produtos naturais aos insetos geralmente ocorre por diversos mecanismos, porém, pode ser específica a determinado grupo de insetos. Esta pode ser constatada por meio de bioensaios onde as substâncias naturais são aplicadas topicamente ou por ingestão (BUENO et al., 1990).

Assim, o presente trabalho tem como objetivo avaliar a atividade inseticida do óleo essencial de $\mathrm{H}$. marrubioides no controle de Zabrotes subfasciatus.

\section{Material e Métodos}

\subsection{Extração do óleo essencial}

A extração do óleo essencial de inflorescências frescas de plantas $H$. marrubioides foi realizada no Laboratório de Cultura de Tecidos e Plantas Medicinais da Universidade Federal de Lavras (UFLA), pelo método de hidrodestilação em aparelho de Clevenger, por uma hora e meia. 0 óleo essencial foi purificado por partição líquido-líquido com diclorometano. A fase orgânica foi reunida e tratada com $5 \mathrm{~g}$ de sulfato de magnésio anidro durante trinta minutos. Após esse período a solução foi filtrada e o solvente evaporado em temperatura ambiente, sob capela de exaustão de gases. 


\subsection{Ensaio biológico}

O ensaio biológico foi conduzido no Laboratório de Microscopia do Instituto Federal do Sul de Minas (IFSULDEMINAS), Campus Muzambinho.

0 delineamento experimental utilizado foi inteiramente casualizado, constituído de cinco concentrações de óleo essencial de H. marrubioides (0,0; 6,25\%; 12,5\%; 25\% e 50\%), com quatro repetições contendo um casal de Z. subfasciatus por repetição.

Um casal, recém-emergido de Z. subfasciatus (0-24h) foi colocado em cada placa de Petri, contendo três grãos de feijão tratados (T) e não tratados (NT). Foi realizada uma marcação longitudinal para separar os grãos tratados dos não tratados, caracterizando assim um ensaio com chance de escolha para o inseto.

O feijão (Phaseolus vulgaris L. cv. Carioca) utilizado no experimento estava isento de qualquer contaminação química.

A aplicação das cinco concentrações do óleo essencial de $\mathrm{H}$. marrubioides foi realizada com uma micropipeta e o volume final de óleo essencial aplicado/grão foi de $5 \mu \mathrm{L}$. Foi realizada a diluição do óleo essencial em álcool $70 \%$ para preparação das concentrações utilizadas no experimento. No tratamento controle (ausência total de óleo essencial), foi aplicado apenas álcool 70\% nos grãos de feijão em um lado da placa de Petri, sendo que no outro lado da placa não foi aplicado. Este procedimento foi adotado para verificar se o solvente utilizado (álcool 70 \%) não interfere na mortalidade dos insetos. A descrição das concentrações utilizadas para realização da diluição do óleo essencial no solvente segue na Tabela 1.

Tabela 1. Preparo das soluções para aplicação nos grãos de feijão.

\begin{tabular}{ll}
\hline Tratamento 1 & 100 microlitros álcool 70\% (Testemunha) \\
Tratamento 2 & 50 microlitros álcool 70\% e 50 microlitros de óleo essencial \\
Tratamento 3 & 75 microlitros álcool $70 \%$ e 25 microlitros de óleo essencial \\
Tratamento 4 & 87,5 microlitros álcool $70 \%$ e 12,5 microlitros de óleo essencial \\
Tratamento 5 & 93,75 microlitros álcool $70 \%$ e 6,25 microlitros de óleo essencial
\end{tabular}

Fonte: Elaboração dos autores

Após quinze dias da montagem dos experimentos, o número de ovos depositados sobre os grãos em cada recipiente foi contado com o auxilio de um microscópio estéreo (lupa) binocular. A mortalidade dos insetos e comportamento foi avaliada durante todo o dia.

Os dados de porcentagem de mortalidade dos insetos e número de ovos depositados foram analisados estatisticamente por análise de variância e posteriormente, foi aplicada análise de regressão e teste de Scott-Knott a 5\% de probabilidade pelo programa SISVAR ${ }^{\circledR}$, versão 5.0 (FERREIRA, 2000).

\section{Resultados e Discussão}

Foi possível realizar a contagem de ovos depositados na superfície dos grãos apenas no Tratamento 1 (Testemunha/sem aplicação de óleo essencial de H. marrubioides). Foi observado nos ovos, coloração amarelo-claro, ocasionada pelo fenômeno de oxidação (Figura 1) e todos os indivíduos de Z. subfasciatus apresentavam vitalidade e mobilidade intensa. A eclosão dos insetos nos grãos ocorreu dezoito dias após a contagem dos ovos.

Os demais tratamentos (com as concentrações de óleo essencial) impediram a oviposição causando a letalidade do Z. subfasciatus. 


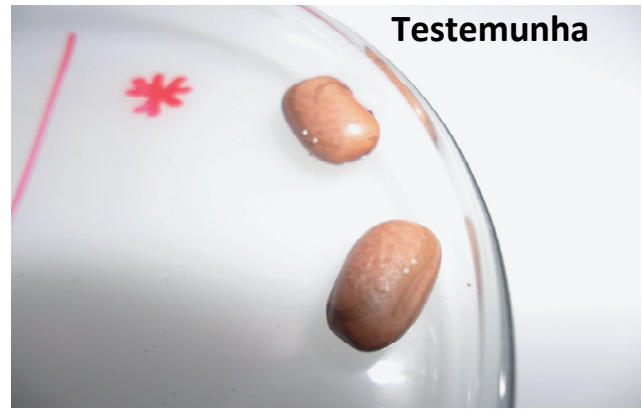

Figura 1. Deposição de ovos de Z. subfasciatus sobre grãos de feijão não tratados com o óleo essencial de $\mathrm{H}$. marrubioides.

De acordo com a Figura 2 é possível observar que não houve diferença significativa para a contagem do número de ovos de indivíduos de Z. subfasciatus com teste de chance de escolha na testemunha (Tratamento 1). Nos grãos tratados com álcool a média foi de 1,84 ovos/grão e nos grãos não tratados com álcool a média foi de 1,17 ovos/grão.

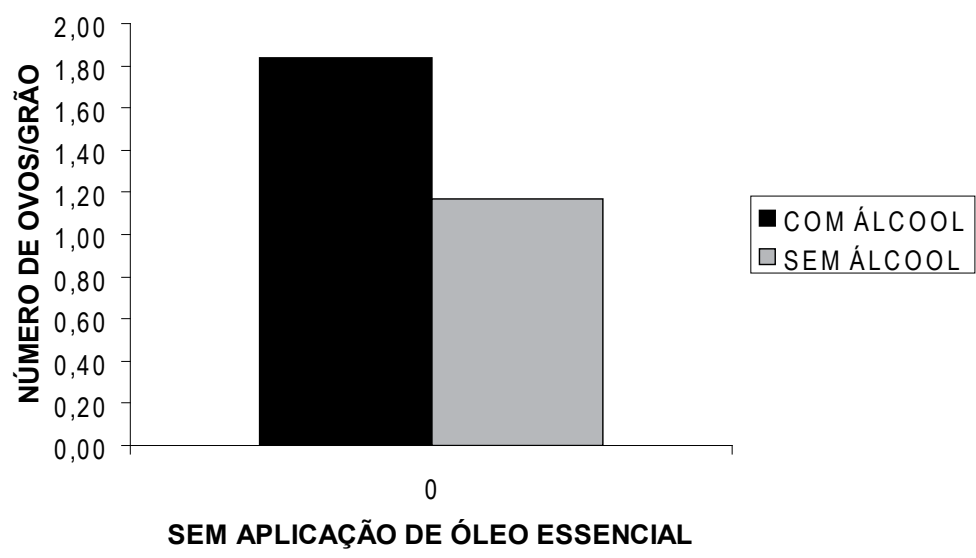

Figura 2. Número médio de ovos de indivíduos de Z. subfasciatus por grão não submetidos a aplicação do óleo essencial de H. marrubioides (com chance de escolha: grãos tratados com álcool e não tratados).

As médias seguidas da mesma letra, não diferem entre si pelo teste de Scott-Knott ao nível de 5\% de probabilidade.

Verificou-se após um minuto da aplicação do tratamento dois (50\% de óleo essencial), que o casal de Z. subfasciatus apresentou alterações visíveis no seu comportamento. Uma intensa agitação motora, perda de orientação espacial e do senso de equilíbrio, fazendo uma rotação ao longo do seu eixo longitudinal, tentando passar por baixo do grão, chegando a deslocá-lo alguns milímetros, atritando seus membros locomotores uns contra os outros em um movimento intenso, chegando até a se enroscarem. Após cinco minutos houve a perda da mobilidade total, chegando a $100 \%$ de mortalidade dos insetos na concentração de $25 \%$ do óleo essencial (Figura 3). Os insetos que entraram em contato direto com o grão na placa morreram em pouco mais de dez segundos e os outros que não tiveram contato direto em aproximadamente cinco minutos.

A mortalidade destes insetos na exposição ao óleo em superfície contaminada, segundo Santos et al. (2007) deve-se, provavelmente, à sua respiração traqueal, localizada lateralmente através de pequenos orifícios (espiráculos), o que favorece a absorção do óleo e, consequentemente, a morte por asfixia.

Nos tratamentos quatro e cinco (12,5 e 6,25 \% de óleo essencial), verificou-se um tempo maior para os insetos chegarem a morte. A perda de mobilidade foi lenta e progressiva, chegando a ficarem imóveis vinte e oito minutos após contato com o grão que recebeu o tratamento (Figura 3).

Nesse sentido, Roel (2001) cita que a influência dos efeitos e o tempo de ação das soluções 
são dependentes da dosagem utilizada, de maneira que a morte ocorre nas dosagens maiores e os efeitos menos intensos e mais duradouros nas dosagens menores.

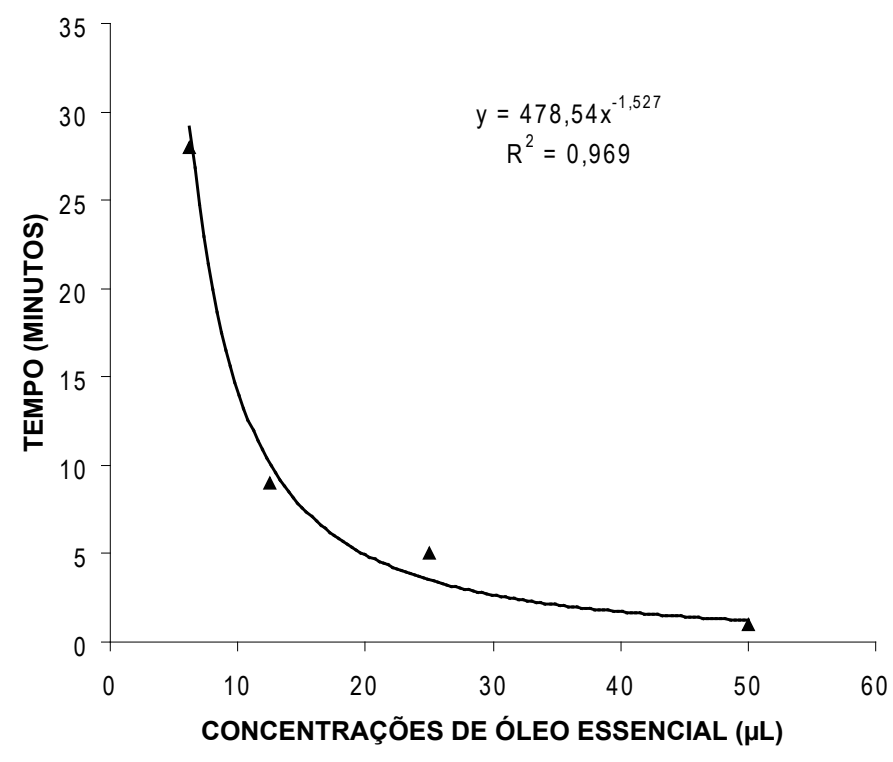

Figura 3. Tempo de mortalidade de indivíduos de Z. subfasciatus em função de diferentes concentrações do óleo essencial de H. marrubioides.

Os Tempos Letais (TL) diminuem conforme há contato direto e aumento da concentração do óleo essencial de H. marrubioides aplicada. Os tratamentos com o óleo essencial mostraram-se efetivos, pois provocaram mortalidade total dos insetos adultos e nenhuma oviposição. Para as quatro concentrações testadas, o intervalo de tempo de vinte e oito minutos foi suficiente para provocar mortalidade de todos os indivíduos.

A atividade inseticida de óleos essenciais pode ocorrer de diversas formas, causando mortalidade, deformações em diferentes estágios de desenvolvimento, repelência e deterrência. A atividade repelente é o modo de ação mais comum dos óleos essenciais e de seus componentes majoritários. Por meio do contato, podem interagir com o tegumento do inseto, além de atuar em enzimas digestivas e neurológicas (ISMAN, 2006). No presente estudo, foi possível observar que o contato dos insetos com as concentrações do óleo essencial de $\mathrm{H}$. marrubioides promoveu a mortalidade mais rápida dos insetos.

O uso de extratos de plantas inseticidas, inclusive os compostos aleloquímicos como os óleos essenciais, foram empregados no controle de insetos antes do advento das substâncias orgânicas sintéticas (REGNALT-ROGER, 1997). Tradicionalmente, o controle de pragas tem sido realizado com aplicações sucessivas de inseticidas e fungicidas sintéticos, porém, o uso contínuo desses produtos tem sido considerado indesejável devido aos efeitos negativos, tais como o desenvolvimento de resistência dos insetos a estes produtos; aparecimento de novas pragas ou ressurgência das existentes; desequilíbrios biológicos; efeitos prejudiciais aos animais e inimigos naturais; além dos elevados custos de aplicação dos produtos (KOGAN, 1998).

0 modo de ação pode estar diretamente relacionado aos compostos terpenóides, como a inibição da acetilcolinesterase (VIEGAS JÚNIOR, 2003). A acetilcolina deve ser removida da fenda sináptica por meio de uma hidrólise catalisada pela acetilcolinesterase. Caso isso não aconteça, ocorre o acúmulo do neurotransmissor na fenda, impedindo uma transmissão correta do potencial de ação, que pode levar o animal à morte por falência respiratória (CHAMBERS; CARR, 1995).

Os mecanismos de ação tóxica dos óleos essenciais ainda não foram bem elucidados, no entanto, o aparecimento de sinais tóxicos é rápido. Dados de Enan (2001) descrevem o inicio da ação tóxica dos óleos essenciais em baratas (Periplaneta americana) com hiperatividade, seguida por hiperextensão das pernas e do abdômen, imobilização e morte. Alguns estudos demonstram que a 
octopamine induz essas reações (LIVINGSTONE et al., 1980; HARRIA-WARRICK et al., 1980), pois desempenha um amplo espectro de funções biológicas em insetos, agindo como neurotransmissor, fator neuro-hormonal ou neuromodulador (ORCHARD, 1982). A octopamine é encontrada em grandes quantidades no sistema nervoso de espécies representativas do filo Arthropoda, incluindo a classe Insecta.

O uso de produtos naturais como matéria-prima para a síntese de substâncias bioativas tem sido amplamente relatado (PAIVA et al., 2005), destacando-se os produtos de origem botânica, cuja diversidade de estruturas químicas permite sua utilização como importantes fontes de recursos para a produção de inseticidas (CASTRO et al., 2005). Plantas com ação inseticida têm sido utilizadas como método alternativo de controle de insetos e praga, por meio de produtos com formulação em pó, óleos e extratos em produtos armazenados (VIEIRA et al., 2004).

\section{Conclusões}

A contagem de ovos de Z. subfasciatus depositados na superfície dos grãos de feijão foi possível de ser realizada apenas na testemunha. Os demais tratamentos impediram a oviposição, causando a mortalidade do Z. subfasciatus.

Os Tempos Letais (TL) diminuem conforme há contato direto e aumento da concentração do óleo essencial de H. marrubioides. O tempo máximo de mortalidade dos insetos foi de vinte e oito minutos, atingido com a concentração de 6,25\% de óleo essencial.

Neste trabalho, foi demonstrando o potencial inseticida do óleo essencial de H. marrubioides, podendo ser de grande utilidade no manejo integrado de Z. subfasciatus em feijão armazenado. Porém, ressalta-se a necessidade de estudos relacionados à identificação do composto químico responsável pela atividade inseticida e posterior padronização química do material vegetal.

\section{Insecticidal Activity of Essential Oil of Hyptis marrubioides Control Zabrotes subfasciatus (Coleoptera, Chrysomelidae, Bruchinae)}

\section{Abstract}

It's known that a large percentage of the bean production and storage is lost by insects. This study aimed to evaluate the insecticidal activity of essential oil of Hyptis marrubioides control Zabrotes subfasciatus. The essential oil extraction was performed by the method of hydrodistillation in a Clevenger apparatus for an hour and a half and biological assay was conducted in the Microscopy Laboratory / IFSULDEMINAS - Campus Muzambinho. The experimental design was completely randomized, with five doses of essential oil $(0.0,6.25 \%, 12.5 \%, 25 \%$ and $50 \%$ ), with 04 replicates a couple of Z. subfasciatus by repetition. We carried out the test and the test of mortality or inhibition of oviposition repellency. 03 grains used was treated with 05 microliters $(\mu \mathrm{L})$ of the solution and three untreated, and that in each petri dish of diameter $9.0 \mathrm{~cm}$ bed 01 had Z. subfasciatus. As a control, we used $100 \mu \mathrm{L}$ of $70 \%$ alcohol. Under each treatment applied, we observed the reaction of individuals depending on the application of the solution in the grains, indicating that the lethal times (LT) decrease as there is an increase of the applied dose and direct contact with the oil of $\mathrm{H}$. marrubioides. The treatments with essential oil proved to be effective, because they caused repellency, total adult mortality and no oviposition. For the four tested doses, the time interval of 28 minutes was sufficient to induce mortality in all individuals. Besides not observe a significant difference in the average number of eggs of individuals of Z. subfasciatus not subject to the application of essential oil of $\mathrm{H}$. marrubioides (free choice: grain alcohol-treated and untreated). Therefore in this study, we observed the insecticidal potential of essential oil of $\mathrm{H}$. marrubioides, which due to its effective insecticidal properties observed in this study may be useful in integrated management of Z. subfasciatus in stored bean.

Key words: Field mint. Medicinal plant. Natural insecticide. Bean weevil. 


\section{Referências Bibliográficas}

ARNASON, J. T.; PHILOGÈNE, B. J. R.; MORAND, P. Insecticide of plant origin. Washington, D.C., American Chemical Society. v. 387, 214 p., 1990.

BELL, A. FELLOWS, L. E.; SIMMONDS, M. S. J. Natural products from plants for the control of insect pests. In: HODGSON, E.; KUHR, R.J. Safer Insecticide development and use. New York and Basel, Marcel Dekker, p.337-383, 1990.

BUENO, O. C. et al. Toxic effect of elants on leaf-cutting ants and their symbiotic fungus. In: VANDER MEER, R. K.; JAFFE, K.; C EDENO, A. (Ed.). Applied Myrmecology: a world perspective, San Francisco: Westview, 1990. p. 420-423.

CASTRO, P.R.C.; KLUGE, R.A.; PERES, L.E.P. Manual de fisiologia vegetal. São Paulo: Agronômica Ceres, 2005. $650 \mathrm{p}$.

CHAMBERS, J. E.; CARR, R. L. Biochemical mechanisms contributing to species differences in insecticidal toxicity. Toxicology, 105, p.291-304, 1995.

ENAN, E. Insecticidal activity of essential oils: octopaminergic sites of action. Comparative Biochemistry and Physiology, 130, p. 325-337, 2001.

FERREIRA, D. F. Análises estatísticas por meio do Sisvar para Windows, versão 4.0. In: REUNIÃO ANUAL DA REGIÃO BRASILEIRA DA SOCIEDADE INTERNACIONAL DE BIOMETRIA, 45. 2000. Anais... São Carlos: UFSCar. 2000. p. 255-258.

HARLEY, R. M. Evolution and distribution of Eriope (Labiatae) and its relatives in Brasil. In: WORKSHOP ON NEOTROPICAL DISTRIBUTION PATTERNS, Rio de Janeiro. Proceedings... Rio de Janeiro: Academia Brasileira de Ciências, 1988, p. 71-80.

HARRIA-WARRICK, R.; LIVINGSTONE, M.; KRAVITZ, E. A. Central effects of octopamine and serotonin o postural motor systems in the lobster. Neuroscience Abstract, 6, p. 27-31, 1980.

HOHMANN, C. L.; S. M. CARVALHO. 1989. Pragas e seu controle. In: Instituto Agronômico do Paraná (org.), 0 feijão no Paraná. Londrina, IAPAR, 1989, , p. 217-246.

ISMAN, M. B. Botanical insecticides, deterrents, and repellents in modern agriculture and an increasingly regulated world. Annual Review of Entomology, v. 51, p. 45-66, 2006.

KOGAN, M. Integrated pest management historical perspectives and contemporary developments. Annual Review of Entomology, v.43, p. 243-270, 1998.

KUHNT, T. M. et al. Biological and pharmacological activities and further constituints of Hyptis verticullata. Planta Medica, Stuttgart, v. 61, n. 3, p. 227-232, 1995.

LIVINGSTONE, M.; HARRIA-WARRICK, R.; KRAVITZ, E. A. Serotonin and octopamine produce opposite postures in lobsters. Science, v. 208, p. 76-79, 1980.

OLIVEIRA, A. M. et al. Incidência de Zabrotes subfasciatus Boheman, 1833 e Acanthoscelides obtectus Say, 1831 em diversas cultivares de feijão armazenado (Col., Bruchidae). Anais da Sociedade Entomológica do Brasil, v. 8, n. 1, p. 47-55, 1979.

ORCHARD, I. Octopamine in insects:neurotransmitter, neurohormone and neuromodilator. Canadian of Journal Zoology, v. 60, p. 659-669,1982.

PAIVA, S. R.; FIGUEIREDO, M. R.; KAPLAN, M. A. C. Estudo fitoquímico de Plumbago auriculata LAM. Revista Fitos, v. 1, n. 2, p. 64-68, 2005.

REGNAULT-ROGER, C. The potential of botanical essential oils for insects pest control. Integrated Pest Management Reviews, v. 2, p. 25-34, 1997. 
ROEL, A. R. Utilização de plantas com propriedades inseticidas: uma contribuição para o desenvolvimento rural sustentável. Revista Internacional de Desenvolvimento Local, v. 1, p. 43-50, 2001.

SANTOS, M. R. A. dos. et al. Atividade inseticida do óleo essencial de Schinus terebinthifolius Raddi sobre Acanthoscelides obtectus Say e Zabrotes subfasciatus Boheman. Boletim de Pesquisa e Desenvolvimento. Embrapa Rondônia. Porto Velho, RO, 13 p, 2007.

SIMÕES, C. M. O.; SPITZER, V. Farmacognosia: da planta ao medicamento. Porto Alegre: UFRGS/Florianópolis: UFSC, 2000.

TEIXEIRA, I. R. V.; ZUCOLOTO, F. S. Seed suitability and oviposition behaviour of wild and selected populations of Zabrotes subfasciatus (Boheman) (Coleoptera, Bruchidae) on different hosts. Journal of Stored Products Research, v. 39, p. 131-140, 2003.

UNITED STATES DEPARTMENT OF AGRICULTURE. Programa Nacional dos Recursos Genetic. Rede de informação dos recursos de Germplasm - Recursos nacionais laboratório de Germplasm. Beltsville, Maryland. Disponível em: <http://www.ars-grin.gov/cgi-bin/npgs/html/family.pl?2099>. Acesso em: $15 / 05 / 2012$.

VIEGAS JÚNIOR, C. Terpenos com atividade inseticida: uma alternativa para o controle químico de insetos. Química Nova, 26: p. 390-400, 2003.

VIEIRA, P. C.; MAFEZOLI, J.; BIAVATTI, M. W. Inseticidas de origem vegetal. In: FERREIRA, J. T. B.; CORREAA, A. G.; VIEIRA, P. C. Produtos naturais no controle de insetos. São Carlos: UFSCar, 176 p., 2001. (Série de Textos da Escola de Verão em Química, v. 3).

VIEIRA, P. C.; FERNANDEZ, J. B.; ANDREI, C. C. Plantas inseticidas. In: SIMÕES, C.M.O. SPITZER, V. (Org.) Farmacognosia: da planta ao medicamento. 5. ed. Porto Alegre: UFRGS; Florianopólis: UFSC, Cap. 35. p. 903-918, 2004.

WILLIS, J. C. Dictionary of flowering plants and ferns. London: Columbia University, 1973.

\section{Histórico editorial}

Recebido: 17/03/2013

Avaliação e copidesque: 27/05/2013 a 28/01/2014 